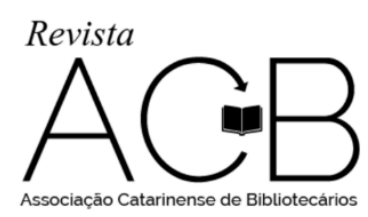

\title{
O AGIR COMUNICATIVO DE HABERMAS EM BIBLIOTECAS COMUNITÁRIAS: UMA ANÁLISE REFLEXIVA SOB A LUZ DA MEDIAÇÃO
}

\author{
Katia Viana Cavalcante ${ }^{1}$ \\ André Luiz Avelino da Silva ${ }^{2}$ \\ Felipe Vlaxio Lopes ${ }^{3}$
}

\begin{abstract}
Resumo: O artigo trata de reflexão sobre bibliotecas comunitárias à luz da Teoria da Ação Comunicativa. A partir do agir comunicativo de Habermas, analisou-se o papel do bibliotecário enquanto mediador e disseminador da informação no universo das bibliotecas comunitárias, bem como a interação social entre os membros da comunidade a partir dos trabalhos de mediação. Por meio de abordagem exploratória, embasada no método fenomenológico, conduziu-se a pesquisa como um estudo de caso que, doravante, ajustou-se a um relato de experiência. Como norte, questiona-se se a biblioteca comunitária é capaz de contribuir para a emancipação de seus interagentes. O resultado da reflexão culmina da importância do mediador atuando frente às particularidades dos interagentes da biblioteca em sua diversidade étnica, religiosa, socioeconômica, etc.
\end{abstract}

Palavra-chave: Biblioteca Comunitária. Mediação. Teoria da Ação Comunicativa.

\section{INTRODUÇÃO}

Ao se considerar que o conhecimento é o resultado de um processo, então, a partir de um raciocínio lógico, é possível deduzir que existem etapas que permitem uma estruturação para esta atividade-fim. Destarte, compete inferir, também, que as etapas do processo prescindem de uma plêiade de ações promovidas por determinados indivíduos, a fim de incutir um produto final passível de verificação em uma realidade observável.

Sendo assim, pode-se especular que tais ações, no composto de uma organização, também admitem requisitos básicos de comunicação, tais como um emissor, um receptor, uma mensagem e um canal pelo qual a mensagem é transferida. Em uma premissa menos floreada, significaria afirmar que, para se obter um fim, é imprescindível que exista um começo e um meio.

Com base nesta perspectiva exploratória, o presente artigo nasceu de uma inquietação fomentada pelo Programa Institucional de Extensão (PIBEX) executado na Biblioteca Comunitária Vilma Palheta, localizada na cidade de Manaus/AM. As atividades foram vinculadas ao Departamento de Arquivologia e Biblioteconomia (DAB) da Universidade Federal do Amazonas (UFAM) no período de agosto de 2013 a outubro de 2014. O projeto fez parte do Programa Coroado, homologado pela Resolução No. 006/2013 instaurada pela Câmara de Extensão e Interiorização da UFAM no referido ano.

\footnotetext{
${ }^{1}$ Doutora em Desenvolvimento Sustentável (UnB-2013).

${ }^{2}$ Graduando em Biblioteconomia pela Universidade Federal do Amazonas (UFAM).

3 Mestrando em Sociedade e Cultura na Amazônia (UFAM).
} 


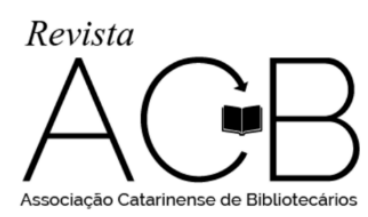

Revista ACB: Biblioteconomia em Santa Catarina, Florianópolis, v. 22, n. 3, p. 534-547, ago./nov., 2017.

A experiência vivenciada no Programa coincidiu com as disciplinas de Introdução à Comunicação, Estudo do Usuário, e Serviço de Referência e Informação, ministradas no curso de Bacharel em Biblioteconomia da UFAM. Partindo da transversalidade entre a teoria e a prática das aulas e das atividades do projeto, obteve-se o seguinte questionamento: De que maneira a Teoria da Ação Comunicativa (HABERMAS, 1997) pode ser identificada no universo de uma biblioteca comunitária e em que medida a mediação contribui para esta realidade?

Para responder a esta indagação e outras perguntas pontuais, optou-se pelo uso de abordagens fenomenológicas, posto que, segundo Triviños (1987), possibilitam uma construção de amostras firmadas na investigação de fenômenos situacionais que afetam diretamente um determinado grupo de indivíduos. Neste caso, a comunidade do bairro Coroado e entornos configuraram-se como objetos de estudo enquanto expoentes da demanda pela biblioteca supramencionada.

Não obstante, Marconi e Lakatos (2003) corroboram que investigações exploratórias de cunho fenomenológico visam à sistematização de dados qualitativos a fim de possibilitar a compreensão do comportamento dos indivíduos envolvidos nos fenômenos estudados. Em linhas gerais, o estudo trilhou a aplicação metodológica priorizando as consequências que os objetos deste estudo impõem à comunidade específica.

A pesquisa justifica-se no métier do bibliotecário no papel de mediador das ações em que a comunicação se apresenta como vital para a disseminação da informação. Em outras palavras, os autores priorizaram o agir comunicativo dentro de bibliotecas comunitárias por entenderem que a teoria de Habermas complementa a necessidade de compreensão acerca do fazer biblioteconômico em uma estrutura organizacional como a estudada neste artigo.

A partir desta linha de pensamento, o principal objetivo deste artigo reside em fomentar uma reflexão acerca do agir comunicativo de Jürgen Habermas no seu papel de mediação em bibliotecas comunitárias. Entretanto, é necessário pontuar dois aspectos importantes para a pesquisa: o primeiro deles diz respeito à reflexão em si, que não trata, em sentido austero, da Biblioteca Comunitária Vilma Palheta, mas, por outro lado, utiliza-se da experiência do programa desenvolvido na instituição como modelo de observação para as especulações que se seguirão no texto.

O segundo aspecto da pesquisa que deve ser ressaltado diz respeito ao uso de terminologia própria para o universo deste artigo. Para este caso específico, foram empregados dois termos que se referem a um mesmo indivíduo, porém, sob perspectivas divergentes. Trata-se dos termos "usuário" — utilizado de 


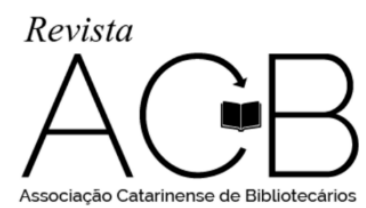

Revista ACB: Biblioteconomia em Santa Catarina, Florianópolis, v. 22, n. 3, p. 534-547, ago./nov., 2017.

modo passivo para representar o indivíduo enquanto consumidor de informação — e "interagente" aplicado, conforme o pensamento de Corrêa (2017), para designar o indivíduo como agente ativo e interacional da informação.

Diante disso, intenciona-se contribuir para a compreensão do funcionamento das bibliotecas comunitárias como organismos vivos e passíveis de ações concretas e intelectuais. Adicionalmente, pretende-se aferir a importância da linguagem em sua função mais básica, que é o exercício da comunicação em favor da criação de um comportamento social no cerne de uma comunidade.

\section{REFLEXÃO ACERCA DO AGIR COMUNICATIVO ENQUANTO PROPOSTA DE MEDIAÇÃO EM BIBLIOTECAS COMUNITÁRIAS}

A Teoria da Ação Comunicativa, de Habermas, produz uma inquietação no indivíduo, incutindo-o a questionar sobre o mundo que o cerca; celebra a crítica como forma de enxergar o meio em que se está inserido, deixando de lado uma visão objetiva e direta, e propondo algo mais interativo entre o sujeito e o meio. Por conseguinte, os indivíduos, munidos de capacidade dialógica, argumentam e discutem entre si a despeito de situações e conflitos a fim de resolvê-los com um pensamento crítico e reflexivo.

$\mathrm{O}$ agir comunicativo de Habermas preconiza uma essência intelectual na qual o objeto mais importante é o consenso. Em outras palavras, os indivíduos de determinada sociedade necessitam conhecer os assuntos sobre os quais delegam argumentações, a fim de que o consentimento entre os agentes sociais seja alcançado sem interpelações de ruídos na linguagem.

Concomitantemente, não basta que uma informação seja disseminada em caráter leviano, mas, para além da mecânica básica da comunicação - com um emissor, um receptor e uma mensagem que a estruturam —, é imprescindível que a informação seja entendida. Isto é, quem emite a mensagem, deve fazê-lo de forma clara, cedendo ao receptor a oportunidade de compreensão.

Se para Luhmann (2005) a informação é autopoiética — capaz de se reproduzir em si mesma —, então para Habermas (GONÇALVES, 1999) a comunicação é consensual — responsável pela publicização de uma ideia a ser acordada por um grupo de indivíduos sociais. Por conseguinte, tem-se uma relação dicotômica, que, portanto, passa a ser espelhada no interagente de uma estrutura organizacional, ou seja, reflete-se no comportamento humano dos indivíduos que orbitam no universo de uma entidade com objetivos traçados. 


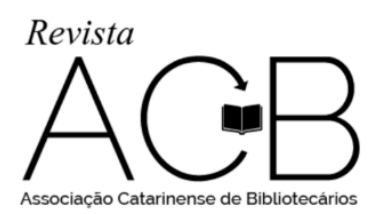

Revista ACB: Biblioteconomia em Santa Catarina, Florianópolis, v. 22, n. 3, p. 534-547, ago./nov., 2017.

A ação comunicativa, desta feita, ostenta como premissa o consenso entre as pessoas, de sorte que os influenciadores sociais que levaram a este mesmo consenso tenham partido de uma relação pública da linguagem, que por sua vez gera a compreensão de um determinado conhecimento disseminado. Isto posto, cabe pontuar que o agir comunicativo de Habermas, doravante, trabalha no sentido de estabelecer dinâmicas inovadoras nos tempos atuais, em todos os campos da vivência humana.

O resultado desse processo de envolvimento entre o indivíduo e o conhecimento à sua volta é o produto da comunicação em si. Entretanto, ao dar à sociedade o poder de decisão sobre suas escolhas, a ação comunicativa acaba por trilhar o caminho inverso de individualizar a dinâmica dos dispositivos sociais. Em outras palavras, embora se pense que a individualidade parta de uma obrigatoriedade separatista, é certo argumentar que, ao contrário, cria-se um comportamento unificante quando, enfim, os desejos e expectativas dos indivíduos são considerados na razão de ser do agir comunicativo.

\begin{abstract}
Chamo ação comunicativa àquela forma de interação social em que os planos de ação dos diversos atores ficam coordenados pelo intercâmbio de atos comunicativos, fazendo, para isso, uma utilização da linguagem (ou das correspondentes manifestações extraverbais) orientada ao entendimento. À medida em que a comunicação serve ao entendimento (e não só ao exercício das influências recíprocas) pode adotar para interações o papel de um mecanismo de coordenação da ação e com isso fazer possível a ação comunicativa. (HABERMAS, 1997, p. 6, grifo do autor, tradução nossa)
\end{abstract}

Partindo dessa linha de raciocínio, Habermas na verdade enfatiza que a comunicação deveria alicerçar a reconstrução da vida social, em um cenário no qual a civilidade da relação pública esteja presente no convívio humano. Destarte, a clarificação das ideias concernentes a assuntos específicos só pode ser alcançada pelas informações às quais os interagentes da sociedade têm acesso, que, por conseguinte, serão compreendidas apenas por intermédio da linguagem, a construtora da comunicação.

Pinto (1995, p. 80) afirma que,

para Habermas, a ação comunicativa surge como uma interação de, no mínimo dois sujeitos, capazes de falar e agir, que estabelecem relações interpessoais com o objetivo de alcançar uma compreensão sobre a situação em que ocorre a interação e sobre os respectivos planos de ação com vistas a coordenar suas ações pela via do entendimento.

Tal perspectiva de escalabilidade ramifica-se de uma concepção de sentido lógico. Se não existe conhecimento, não existe linguagem. Se não existe linguagem, não existe comunicação. E se não existe comunicação, não existe socialização. Esta estrutura do pensar corrobora o pressuposto semiótico do 


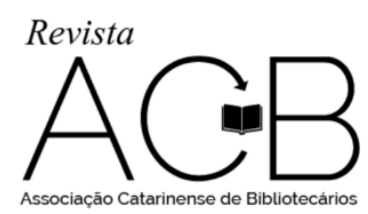

Revista ACB: Biblioteconomia em Santa Catarina, Florianópolis, v. 22, n. 3, p. 534-547, ago./nov., 2017.

comportamento humano, como postulado por Umberto Eco (1991) no final do século XX, quando o autor retratava um nexo semântico entre a linguagem e o exercício da civilidade, resultando em um tipo de comunicação participativa, proativa, autônoma, na qual a ação de um primeiro indivíduo em relação a um segundo indivíduo é o que mais pesa sobre a constância da sociedade.

"Não é a quantidade de informação emitida que é importante para a ação, mas antes a quantidade de informação capaz de penetrar o suficiente num dispositivo de armazenamento e comunicação, de modo a servir como gatilho para a ação". (WIENER, 1991 apud PIGNATARI, 2003, p. 14). A afirmação enfatiza que exaustividade não pode significar qualidade no que tange ao número de resultados obtidos em uma busca. Contudo, para entender de que forma se qualifica o conteúdo recuperado, é necessário compreender a máquina administrativa da instituição para traçar requisitos de avaliação posteriores.

Dentro de uma organização como a biblioteca comunitária, identificar os degraus das estruturas organizacionais pode se tornar um cadafalso para o pesquisador, pois, a priori tomar ciência do universo da comunidade à qual pertence a biblioteca é um trabalho delicado. Isto porque se deve observar não apenas o comportamento do interagente, mas dos funcionários da organização enquanto propiciadores da interação.

A simples existência de um maneirismo sistêmico e tecnicista dentro da biblioteca não significa que a máquina administrativa funcione corretamente. Em outras palavras, é difícil afirmar que há, dentro de uma biblioteca comunitária, um sistema com características autônomas. No resultado do trabalho, será sempre o fator humano que imperará na entrega dos serviços.

Exemplo disto é o termo biblioteca comunitária, que possui divergências, como atesta Machado (2008, p. 52): “percebemos a dificuldade na sua definição, pois ele vem sendo empregado, pela sociedade em geral, como sinônimo de biblioteca pública e biblioteca popular [...], o mesmo ocorre no contexto acadêmico". Porém, quando se propõe uma conceituação mais especulativa, poder-se-ia afirmar deste tipo de biblioteca que requer a frequência de um público diverso, de comportamentos angulares e práticas características de uma comunidade específica. Como consequência, o sistema autônomo dependeria da interação orquestrada tanto pelos funcionários quanto pelos interagentes, a fim de possibilitar uma coreografia organizacional à biblioteca comunitária.

Longe de ser uma crítica ao métier dos agentes de bibliotecas comunitárias, o funcionamento da organização parece desprender-se do agir comunicativo, posto que, tal como visto na Biblioteca 


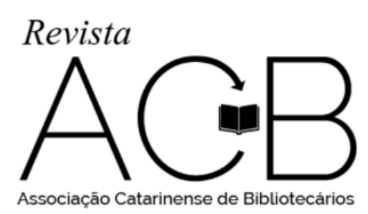

Revista ACB: Biblioteconomia em Santa Catarina, Florianópolis, v. 22, n. 3, p. 534-547, ago./nov., 2017.

Comunitária Vilma Palheta, a ponte entre os funcionários e os usuários em relação aos serviços de referência e informação estagnou-se nas barreiras da comunicação.

Se por um lado o universo das tipologias de bibliotecas é divergente, por outro, o objetivo das bibliotecas de um modo geral é o mesmo. Nesse sentido, cabe o seguinte questionamento: a biblioteca comunitária contribui para a emancipação de seus interagentes? E, por emancipação, leia-se o termo enquanto abrangente, principalmente, das características sociais, intelectuais e críticas.

A resposta para tal indagação emerge à superfície do pensamento antropológico de maneira negativa. Não, a biblioteca comunitária não contribui para a emancipação de seus interagentes — pelo menos, não no sentido autônomo. Não se trata de uma afirmação dura, mas, ao contrário, de uma concepção realista de que a biblioteca comunitária não se sustenta em si mesma, por isso, sem o agir comunicativo da sociedade, é incapaz de ir além da literalidade de seu universo físico.

Mas, então, de que modo pode a biblioteca comunitária, factualmente, contribuir para a emancipação de seus interagentes? Seguindo um rumo oposto ao da premissa anterior, pode-se argumentar que, se não é autônoma, a biblioteca comunitária ganha representatividade por meio da interação social. Mais especificamente, isto acontece a partir dos trabalhos de mediação.

As estruturas organizacionais, segundo Cury (1994), existem para dar sustentação à determinada instituição. Por conseguinte, as estruturas são construídas a partir de fluxos de trabalhos específicos que, quando completos, resultam na entrega de serviços e/ou produtos. Todavia, à cada etapa do fluxo de trabalho incumbe-se um agente responsável. Logo, o processo de organização e métodos da entidade não é possível sem a manipulação humana, que surge na forma de mediação entre um começo e um fim (SPUDEIT; VIAPIANA; VITRORINO, 2010).

Ao trazer a biblioteca comunitária para este cenário, compete preferivelmente ao bibliotecário a função de mediador - muito embora nem sempre exista um bibliotecário graduado no posto. Enquanto trabalha a mediação, o responsável pela biblioteca passa a munir-se de uma plêiade de competências próprias — formação multidisciplinar, por exemplo — para servir de intermediário entre o interagente e a sua necessidade informacional.

Contudo, deve-se levar em conta que uma biblioteca comunitária não exerce apenas sua função austera de disseminar informação, mas, por pressuposto, expande sua atuação para atividades de promoção cultural, incentivo à leitura, acesso à tecnologia, difusão da ludicidade, entre outras. Diante 


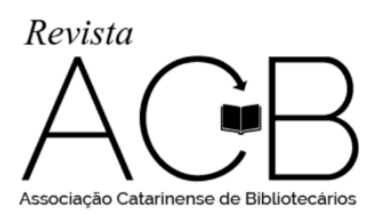

Revista ACB: Biblioteconomia em Santa Catarina, Florianópolis, v. 22, n. 3, p. 534-547, ago./nov., 2017.

disso, o mediador agrega um caráter propulsor ao funcionamento da máquina administrativa da organização.

Na visão de Spudeit, Viapiana e Vitorino (2010), a mediação vai além do fator humano em sua relação com as máquinas. Adicionalmente, ainda de acordo com as autoras, a mediação é especialmente encorajada na modalidade educacional, na qual o bibliotecário age de modo a complementar as necessidades dos interagentes em detrimento ao aprendizado escolar.

Cruzando a premissa do mediador com a ação comunicativa de Habermas, a biblioteca comunitária necessita passar por algumas reflexões acerca do fazer biblioteconômico. Os procedimentos mecanicistas existem para automatizar os serviços, mas é imprescindível que se questione até que ponto a sistematização é obrigatória.

Considere-se, em nível prático, a atividade de indexação. Uma das etapas mais importantes é a tradução da linguagem natural para a linguagem documentária, a fim de que a recuperação da informação — em catálogos, índices, softwares, etc. — seja feita mais dinâmica e rapidamente. Consistiria em transformar, por exemplo, a expressão "dor de cabeça” (linguagem natural — usada popularmente) no ponto de acesso "cefaleia” (linguagem documentária — para os âmbitos acadêmico e científico).

Entretanto, no universo de uma comunidade - com suas diversidades étnicas, religiosas, socioeconômicas, etc. —, seria recomendável que se fizesse a entropia da atividade, isto é, a reversão sistêmica, neste caso, da segunda etapa da indexação. O ponto de acesso "cefaleia", portanto, seria traduzido para a expressão "dor de cabeça", de modo que a linguagem utilizada pela maior parte dos interagentes fosse priorizada, possibilitando a recuperação da informação para o público da biblioteca.

O mediador deve ser capaz de identificar este tipo de particularidade, e, então, trabalhar para atender as demandas da biblioteca. A ação comunicativa de Habermas, doravante, reflete-se no consenso social de que a linguagem natural é mais acessível que a linguagem documentária no universo de uma comunidade plural. As metamorfoses empregadas no trabalho de mediação terão resultados a longo prazo, quando, enfim, a biblioteca comunitária passar, factualmente, a contribuir para a emancipação de seus interagentes.

$\mathrm{O}$ viés da mediação torna-se ainda mais perceptível à luz da interdisciplinaridade que o pensamento complexo cede à sociedade. Para Morin (2008), a mediação liquefaz o conceito “disciplinar” e o dilui até torná-lo homogêneo. Isto é, ao invés de se pensar no conhecimento como caixas separadas, tal como uma lógica linear, é preferível que se o encare como uma rede de conexões com dimensões que figuram entre 


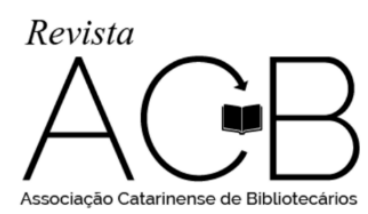

Revista ACB: Biblioteconomia em Santa Catarina, Florianópolis, v. 22, n. 3, p. 534-547, ago./nov., 2017.

as mais diversas disciplinas do saber, tal como uma lógica de teia. A partir disso é que se pode pensar em interdisciplinaridade.

Deste modo, cabe pressupor que a mediação praticada nas bibliotecas comunitárias deve ser constituída de um conjunto de redes de conexões - que, ad hoc, apresentam-se no corpo da interação plurissignificativa entre o bibliotecário e os interagentes - a fim de que a emancipação proporcionada no âmbito da biblioteca condicione-se em estado permanente. Desta feita, o agir comunicativo dispensa o comportamento passivo e assume a função ativa de ferramenta para os envolvidos no processo de interação.

Adicionalmente, existe certa complexidade no cotidiano de uma comunidade, ainda mais no que diz respeito às visões de mundo e em como se encara o conhecimento. Concernente a esta premissa, Barbosa (2015) reitera que a produção intelectual parte de um hábito firmado a partir do cotidiano em detrimento de um comportamento regular. Tal comportamento, no âmbito de uma comunidade, ramifica-se em um caleidoscópio de hábitos configurados na busca da informação, ou seja, o comportamento usual dos interagentes da biblioteca prescinde de uma raiz complexa, de sorte que o fomento do conhecimento e a necessidade do mesmo se concatenam exatamente na interdisciplinaridade causal da emancipação.

Quando se observa a interação ocorrida em uma biblioteca comunitária, tal como favorecida pelas atividades de mediação, tem-se o que Lopes (2000) caracteriza como microfenômeno comunicacional. Para o autor — que também se baseia na obra de Habermas —, a ligação entre bibliotecário e usuários decorre de uma expressão humana com foco na comunicação, portanto, identificável e passível de estudo. Entretanto, por ser um processo de menor escala - visto que se concretiza no universo de uma comunidade —, pode ser categorizado como um microfenômeno.

Partindo desta linha de raciocínio, é possível encarar a mediação como uma atividade com características essencialmente facilitadoras, mas que caminha para além disto. Considere-se, por exemplo, um projeto de incentivo à leitura. Dentro da biblioteca comunitária, há inúmeras formas de se trabalhar a promoção de prazer do interagente enquanto este lida com a leitura. Por conseguinte, tal ação apenas adquire uma raiz ativa quando, de fato, passa a circular entre bibliotecários e usuários. Diante disso, a mediação funciona necessariamente como atividade facilitadora do hábito de leitura incutido no interagente, que, por sua vez, foi acometido por uma ação prévia do projeto da instituição, sendo, portanto, um resultado do agir comunicativo concebido na visão de Habermas. 


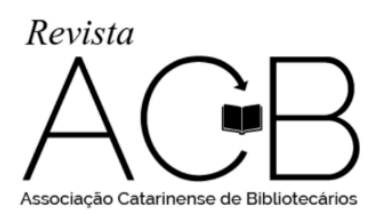

Revista ACB: Biblioteconomia em Santa Catarina, Florianópolis, v. 22, n. 3, p. 534-547, ago./nov., 2017.

Nesse sentido, o protótipo da massa, ou seja, a cultura de grandes demografias (MERTON; LAZARFELD, 2011), toma a silhueta de um microfenômeno no qual é possível identificar um nexo interdisciplinar, por meio da mediação, entre as estruturas organizacionais, os agentes responsáveis pelos fluxos de trabalho - neste artigo, evidenciados na biblioteca comunitária - e os interagentes. Em uma lógica transversal, a referida perspectiva assume como essência primordial o conhecimento demandado por uma comunidade específica.

\begin{abstract}
Os intérpretes renunciam à superioridade de posição privilegiada do observador, porque eles próprios se veem envolvidos nas negociações sobre o sentido e a validez dos proferimentos. Ao tomarem parte em ações comunicativas, aceitam por princípio o mesmo status daqueles cujos proferimentos querem compreender. Eles não estão mais imunes às tomadas de posição por sim/não dos sujeitos de experiência ou dos leigos, mas empenham-se num processo de crítica recíproca. No quadro de um processo de entendimento mútuo-virtual ou atual, não há nada que permita decidir a priori quem tem de aprender de quem. (HABERMAS, 1997, p. 16, tradução nossa).
\end{abstract}

A partir desta afirmação, observou-se que durante as reuniões realizadas na biblioteca do projeto não havia distinção entre os funcionários da unidade; todos os membros compartilhavam suas opiniões e eram ouvidos igualmente, tendo o direito para sugerir, criticar, avaliar e contribuir. Por meio desta interação, com a troca de opiniões, eram decididos quais caminhos tomar acerca de atividades executadas na biblioteca, os sujeitos figuravam no mesmo patamar e realizavam críticas que ajudavam a chegar a um entendimento consensual através das discussões.

Os eventos promovidos pela biblioteca, fruto das reuniões e discussões, tinham como objetivo secundário atrair público para movimentação e utilização do acervo. Para tanto, as ações se voltavam para a promoção de eventos culturais, exposições artísticas e empoderamento intelectual por meio de acesso ao conhecimento. Essa autonomia no planejamento das atividades, definidas pela comunidade, buscava dar aos membros uma emancipação acerca do caminhar da biblioteca.

Não obstante, o conhecimento deve passar por uma curadoria mínima a fim de que seja disponibilizado ao usuário pronto para consumo. As técnicas de curadoria, doravante, apresentam-se como técnicas de tratamento da informação — sejam de descrição física ou de conteúdo —, tal como supracitado nos casos de linguagens natural e documentária.

Em outras palavras, "curar", para a reflexão deste artigo, também faz parte do agir comunicativo observado nas bibliotecas comunitárias. Mas em que sentido? A bem da verdade, a teoria da Habermas adapta-se de sua virtude concreta para uma prática intelectual. Até agora, propôs-se a ação da 


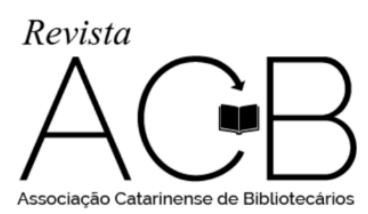

Revista ACB: Biblioteconomia em Santa Catarina, Florianópolis, v. 22, n. 3, p. 534-547, ago./nov., 2017.

comunicação como um comportamento subserviente à realidade observável. Todavia, também se faz mister pontuar que as ações verificadas na teoria partem de um pressuposto originalmente mental para, só então, tornarem-se uma ação real.

Como isto é possível? Uma resposta plausível a este questionamento se apresenta nos campos da semiótica. Para Santo Agostinho na Idade Média, por exemplo, as palavras faladas eram o resultado de palavras mentais (COBLEY; JANSZ, 1997, tradução nossa). Posteriormente, ainda de acordo com os autores, Guilherme de Occam e John Locke trabalharam com conceitos parecidos, segundo os quais uma ação praticada na realidade observável teve sua origem no campo das ideias e, portanto, usufrui de uma raiz intelectual, salvos os casos em que o instinto impera sobre a condição humana.

Quanto a isto, Maturana e Varela (2011) argumentam que, diante do conhecimento, é indispensável conhecer o conhecer. Se o Homo sapiens tornou-se Homo sapiens sapiens, então, infere-se que o conhecimento não é apenas armazenado, mas tomado em ciência. O homem não sabe, puramente. $\mathrm{Na}$ conjuntura humana do ápice da evolução intelectual, o homem sabe que sabe, portanto, está ciente do que é conhecer o conhecer.

Dentro do agir comunicativo, o custo desta intelecção do indivíduo corrobora-se na assertiva de que o homem é, outrossim, um ser não apenas racional, mas igualmente social. Se assim o é, ora, então a comunicação passa a ser a forma na qual se moldam as ações humanas em detrimento de uma sociedade. Para além das concepções antropológicas desse pensamento, quando se tenta aplicar tal prisma ao universo da biblioteca comunitária, compete afirmar que tanto agente (bibliotecário) quanto interagente (usuário) são o resultado de uma interação cognitiva em que a ação comunicativa embasa o comportamento social dentro das estruturas organizacionais.

Nesse caso, a diferença mais tangente entre um e outro está na prerrogativa do bibliotecário enquanto mediador. $\mathrm{O}$ interagente reage às ações do agente, e passa a produzir ações novas, próprias e distintas, possibilitando a propagação da comunicação como escopo da ferramenta social de interação. Logo, quando o resultado de todo o processo é positivo, satisfaz-se a premissa de consenso, que é um dos pilares da teoria de Habermas.

Diante disso, o agir comunicativo evoca a mediação como proposta de interação social definida com características informacionais. Se em uma biblioteca comunitária existe a interdisciplinaridade observável ou não - então cabe reiterar que as ações executadas no universo da comunidade com 


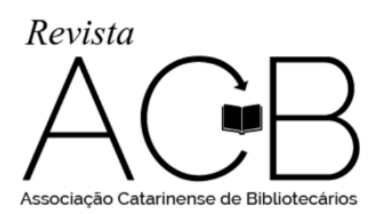

Revista ACB: Biblioteconomia em Santa Catarina, Florianópolis, v. 22, n. 3, p. 534-547, ago./nov., 2017.

participação da biblioteca passam a ser uma única célula social, em cujo âmbito andam juntas as premissas de integridade, confiabilidade, ação comunitária e comunicação participativa.

\section{CONSIDERAÇÕES FINAIS}

Não é segredo que a realidade de um grupo social está repleta de comportamentos identificáveis, quantificáveis e qualificáveis dentro das teorias da comunicação. Entretanto, é consideravelmente raro encarar os dispositivos sociais pelo ponto de vista teórico, pois, enquanto indivíduos participativos da sociedade, torna-se incomum observar o universo à volta sob prismas que trazem novas luzes à compreensão da condição humana. Por esse motivo, quando se propõe o inverso deste caminho, talvez se encontrem situações de difícil entendimento.

A premissa da teoria de Habermas é desses assuntos de fácil internalização, porém, apresenta uma plêiade de vieses para a observância da sociedade, tanto no sentido empírico quanto no sentido antropológico. Em se tratando do agir comunicativo desdobrado na obra do pensador alemão, existe um embasamento na esfera pública que culmina de um estudo esmiuçado acerca do comportamento do ser social inserido em estruturas organizacionais indispensáveis para o funcionamento da coisa pública.

Dentro desta concepção, o artigo analisou o agir comunicativo no âmbito de uma biblioteca comunitária, usando-a como escopo para refletir sobre a ação comunicativa nestas tipologias de bibliotecas de modo geral. As assertivas verificadas partiram da experiência dos autores na vivência do cotidiano da biblioteca em evidência. Para tanto, foram consideradas as principais atividades desenvolvidas no espaço da unidade, tais como reuniões periódicas de cunho administrativo para planejamentos estratégico-tático-operacionais, bem como eventos de promoção da cultura e o uso tradicional do acervo.

Habermas trabalha a partir de um paradigma na linguagem da comunicação, que porventura influencia diretamente nas ações dos indivíduos pertencentes a uma comunidade com claras características de socialização. Quando se traz este raciocínio para a especificidade da biblioteca comunitária, é possível inferir duas assertivas, uma no campo físico de uma realidade observável, e outra na órbita da intelecção humana.

A primeira delas diz respeito ao conceito de mediação enquanto ferramenta do agir comunicativo. Se a ação promulgada a partir da comunicação prescinde de um começo, um meio e um fim — que, neste 
caso, categorizam-se na informação (começo) e no interagente que busca o conhecimento (fim) —, então, por pressuposto, o bibliotecário (meio) assume o papel de mediador exatamente porque medeia a interação entre as partes, comportando-se também como provedor e curador do fluxo da informação em todo seu ciclo.

Para que isso aconteça, faz-se auspicioso que o bibliotecário seja um profissional de formação multidimensional, de sorte que a interdisciplinaridade seja priorizada no âmbito da biblioteca. Desta forma, as necessidades informacionais da comunidade-usuária da unidade serão cobertas em sua grande maioria, e as necessidades não amparadas podem ser operacionalizadas a fim de que sejam atendidas em futuro próximo.

A segunda inferência do artigo concerne ao tratamento da informação para disseminação seletiva ao acesso por parte do interagente. Fazem parte desta ação comunicativa a investigação das linguagens mais adequadas para a recuperação da informação pela comunidade, bem como a curadoria do conhecimento, que se qualifica nos processos de seleção, organização, avaliação e disponibilização da informação contida no acervo da biblioteca.

Este agir comunicativo não é identificável com facilidade na subserviência à realidade observável, posto que, ao invés de uma ação real, ilustra um comportamento tecnicista do mediador, porém, sem desconsiderar as especificidades da comunidade. Ou seja, compete ao bibliotecário o poder de decisão acerca da entropia do processo, tal como visto nas reentrâncias semióticas de Santo Agostinho, Guilherme de Occam e John Locke.

Por conseguinte, na inquietação dos autores deste artigo, questionou-se como a teoria de Habermas pode ser observada na realidade de uma biblioteca comunitária, e qual o papel da mediação neste universo. A resposta para tal indagação concretiza-se no potencial emancipador do trabalho conjunto entre agentes, interagentes e a comunicação. Isto é, vivifica-se na dependência — ainda que interdisciplinar - dos atores que atuam na biblioteca comunitária, e que, doravante, proporcionam a extração de conhecimentos plurissignificativos da interação linguística — verbal e não-verbal — nos moldes da esfera pública.

\section{REFERÊNCIAS}

BARBOSA, Walmir de Albuquerque. Lições sobre o cotidiano: a construção teórica para a análise científica do cotidiano. Manaus: Valer/FAPEAM, 2015. 
COBLEY, Paul; JANSZ, Litza. Introducing semiotics. Londres: Icon Books, 1997.

CORRÊA, Elisa Cristina Delfini. Gestão de estoques de informação: novos termos e novas posturas para um novo contexto. São Paulo: FEBAB, 2017.

CORTELLA, Mario Sergio; DIMENSTEIN, Gilberto. A era da curadoria: o que importa é saber o que importa! Campinas, SP: Papirus 7 Mares, 2015. 122 p. (Coleção Papirus Debates).

CURY, Antonio. Organização \& métodos: uma visão holística. 6. ed. São Paulo: Atlas, 1994.

ECO, Umberto. Semiótica e filosofia da linguagem. São Paulo: Ática, 1991.

GONÇALVES, Maria Augusta Salin. Teoria da ação comunicativa de Habermas: possibilidades de uma ação educativa de cunho interdisciplinar na escola. Educação \& Sociedade, Vale do Rio dos Sinos, v. 10, n. 66, abr. 1999. Disponível em: http://www.scielo.br/pdf/es/v20n66/v20n66a6.pdf. Acesso em: 21 fev. 2017.

HABERMAS, Jürgen. Teoria de la acción comunicativa: complementos y estúdios prévios. Madri: Catedra, 1997.

LOPES, Luís Carlos. De Hermes aos exus: comunicação e moral nos microfenômenos comunicacionais.

Ciberlegenda, Rio de Janeiro, n. 3, 2000. Disponível em:

http://www.ciberlegenda.uff.br/index.php/revista/article/view/278. Acesso em: 24 mar. 2017.

LUHMANN, Niklas. A realidade dos meios de comunicação. São Paulo: Paulus, 2005.

MACHADO, Elisa Campos. Bibliotecas comunitárias como prática social no Brasil. 2008. 184 f. Tese (Doutorado em Ciência da Informação) - Escola de Comunicação e Artes, Universidade de São Paulo, São Paulo, 2008. Disponível em: http://www.teses.usp.br/teses/disponiveis/27/27151/tde-07012009-172507/pt-br.php. Acesso em: 19 fev. 2017.

MARCONI, Marina de Andrade; LAKATOS, Eva Maria. Fundamentos da metodologia científica. 5. ed. São Paulo: Atlas, 2003.

MATURANA, Humberto R.; VARELA, Francisco J. A árvore do conhecimento: as bases biológicas da compreensão humana. 9. ed. São Paulo: Palas Athena, 2011.

MERTON, Robert K.; LAZARFELD, Paul F. Comunicação de massa, gosto popular e a organização da ação social. In: LIMA, Luiz Costa (Org.). Teoria da cultura de massa. 8. ed. São Paulo: Paz e Terra, 2011. p. 94-117.

MORIN, Edgar. Introdução ao pensamento complexo. 5. ed. Lisboa: Instituto Piaget, 2008. (Coleção Epistemologia e Sociedade).

PIGNATARI, Décio. Informação, linguagem, comunicação. São Paulo: Ateliê, 2003.

PINTO, José Marcelino de Rezende. A teoria da ação comunicativa de Jürgen Habermas: conceitos básicos e possibilidades de aplicação à administração escolar. Paidéia, Ribeirão Preto, fev./ago. 1995. Disponível em: http://www.scielo.br/scielo.php?script=sci_arttext\&pid=S0103-863X1995000100007. Acesso em: 12 jan. 2017.

SPUDEIT, Daniela F. A. Oliveira; VIAPIANA, Noeli; VITORINO, Elizete Vieira. Bibliotecário e educação a distância (EAD): mediando os instrumentos do conhecimento. Revista ACB: Biblioteconomia em Santa Catarina, 
Florianópolis, v.15, n.1, p. 54-70 jan./jun., 2010. Disponível em:

https://revistaacb.emnuvens.com.br/racb/article/view/695/0. Acesso em: 25 nov. 2016.

TRIVIÑOS, Augusto Nibaldo Silva. Introdução à pesquisa em ciências sociais: a pesquisa qualitativa em educação. São Paulo: Atlas, 1987.

\title{
HABERMAS' COMMUNICATIVE ACTING IN COMMUNITY LIBRARIES: A REFLEXIVE ANALYSIS UNDER THE LIGHT OF MEDIATION
}

\begin{abstract}
The paper concerns about a reflection on communitarian libraries under the perspective of the Communicative Action Theory. From Habermas's communicative acting, the paper focus on the librarian's role as an information disseminator and mediator in the universe of communitarian libraries, as much as in the social interaction between members of the community after the mediation works. Using an exploratory approach, based on the phenomenological method, we conducted the research as case study, which, further on, we adjusted to an experience report. As a focal point, the authors question whether if the communitarian library is able to contribute to the emancipation of it interagents. The results show the importance of the mediator playing his role with the particularities of the library's interagents in its ethnic, religious and socioeconomic diversity.
\end{abstract}

Keyword: Communitarian Library. Mediation. Communicative Action Theory.

\section{KATIA VIANA CAVALCANTE}

Doutora em Desenvolvimento Sustentável (UnB-2013), mestre em Comunicação e Semiótica (PUC-SP1998). Professora da Universidade Federal do Amazonas, Faculdade de Informação e Comunicação. Email: kcavalcante@ufam.edu.br

\section{ANDRÉ LUIZ AVELINO DA SILVA}

Graduando em Biblioteconomia pela Universidade Federal do Amazonas (UFAM). E-mail: andre_luiz93@live.com

\section{FELIPE VLAXIO LOPES}

Mestrando em Sociedade e Cultura na Amazônia (UFAM), graduado em Biblioteconomia (UFAM-2017). Professor da Universidade Federal do Amazonas, Faculdade de Informação e Comunicação. E-mail:

felipevlaxio@gmail.com

\section{RECEBIDO EM: 19-04-2017}

ACEITO EM: 18-12-2017 